\title{
Inhibition of growth hormone action improves insulin sensitivity in liver IGF-1-deficient mice
}

\author{
Shoshana Yakar, ${ }^{1}$ Jennifer Setser, ${ }^{1}$ Hong Zhao, ${ }^{1}$ Bethel Stannard, ${ }^{1}$ Martin Haluzik, ${ }^{1}$ \\ Vaida Glatt, ${ }^{2}$ Mary L Bouxsein, ${ }^{2}$ John J. Kopchick, ${ }^{3}$ and Derek LeRoith ${ }^{1}$ Maryland, USA
${ }^{2}$ Department of Surgery, Beth Israel Deaconess Medical Center and Harvard Medical School, Boston, Massachusetts, USA ${ }^{3}$ Edison Biotechnology Institute, Ohio University College of Osteopathic Medicine, Ohio University, Athens, Ohio, USA \\ ${ }^{1}$ Diabetes Branch, National Institute of Diabetes and Digestive and Kidney Diseases, National Institutes of Health, Bethesda
}

\begin{abstract}
Liver IGF-1-deficient (LID) mice have a 75\% reduction in circulating IGF-1 levels and, as a result, a fourfold increase in growth hormone (GH) secretion. To block GH action, LID mice were crossed with $\mathrm{GH}$ antagonist $(\mathrm{GHa})$ transgenic mice. Inactivation of GH action in the resulting LID + GHa mice led to decreased blood glucose and insulin levels and improved peripheral insulin sensitivity. Hyperinsulinemic-euglycemic clamp studies showed that LID mice exhibit severe insulin resistance. In contrast, expression of the GH antagonist transgene in LID + GHa mice led to enhanced insulin sensitivity and increased insulin-stimulated glucose uptake in muscle and white adipose tissue. Interestingly, LID + GHa mice exhibit a twofold increase in white adipose tissue mass, as well as increased levels of serumfree fatty acids and triglycerides, but no increase in the triglyceride content of liver and muscle. In conclusion, these results show that despite low levels of circulating IGF-1, insulin sensitivity in LID mice could be improved by inactivating GH action, suggesting that chronic elevation of GH levels plays a major role in insulin resistance. These results suggest that IGF-1 plays a role in maintaining a fine balance between GH and insulin to promote normal carbohydrate and lipid metabolism.
\end{abstract}

J. Clin. Invest. 113:96-105 (2004). doi:10.1172/JCI200417763.

\section{Introduction}

More than 60 years ago Houssay and colleagues described hypersensitivity to insulin in hypophysectomized (hypox) animals (1). Since then, investigators have tried to define the role of growth hormone $(\mathrm{GH})$ in carbohydrate and lipid metabolism. Animal and human studies have shown that GH injection has both acute and chronic effects on carbohydrate and lipid metabolism. The acute effects of GH injection are considered to be insulin-like, as demonstrated in hypox animals, hypopituitary subjects, and in children with idiopathic GH deficiency $(2,3)$. Under these conditions, acute injection of GH decreases blood glucose levels, stimulates

Received for publication January 3, 2003, and accepted in revised form October 14, 2003.

Address correspondence to: Derek LeRoith, Diabetes Branch, National Institute of Diabetes and Digestive and Kidney Diseases, National Institutes of Health, Room 8D12, Building 10, Bethesda, Maryland 20892-1758, USA. Phone: (301) 496-8090;

Fax: (301) 480-4386; E-mail: derek@helix.nih.gov.

Conflict of interest: The authors have declared that no conflict of interest exists.

Nonstandard abbreviations used: hypophysectomized (hypox); growth hormone (GH); triglyceride (TG); lipoprotein lipase (LPL); hormone-sensitive lipase (HSL); insulin receptor (IR); GH receptor (GHR); insulin receptor substrate-1 (IRS-1); suppressors of cytokine signaling (SOCS); liver IGF-1-deficient (LID); GH antagonist (GHa); white adipose tissue (WAT); albumin-enhancer promoter sequence (Alb-Cre); fatty acids (FAs); glucose- 6 phosphatase (G6Pase); phosphenolpyruvate carboxy kinase (PEPCK); acetyl-CoA carboxylase (ACC); carnitine

palmitoyltransferase I (CPTI); brown adipose tissue (BAT). skeletal muscle glucose uptake, and increases glucose transport and lipogenesis in isolated adipocytes $(2,3)$. These acute effects of GH are transient, however, and their physiological significance is unclear. The chronic effects of GH are considered to be anti-insulin, and they include increased blood glucose concentrations, decreased peripheral insulin sensitivity despite higher levels of insulin secretion, decreased insulin-stimulated glucose uptake in muscle, increased hepatic glucose production, and stimulation of lipolysis (3). The lipolytic effects of chronic GH treatment include decreased adiposity, reduced triglyceride (TG) accumulation resulting from inhibition of lipoprotein lipase (LPL), and increased hormone-sensitive lipase (HSL) activity $(4,5)$.

The molecular mechanism of GH-induced insulin insensitivity is not clear. GH does not directly regulate insulin receptor (IR) levels, though it was demonstrated in several animal models that GH deficiency leads to an upregulation of IR levels (6). There is no direct interaction between the GH receptor (GHR) and the IR. There are, however, downstream signaling events following insulin and GH stimulation that may converge at a postreceptor level. GH has been shown to promote tyrosine phosphorylation of the IR substrate-1 (IRS-1) and IRS- 2 proteins by activation of JAK2 $(7,8)$. It has also been shown that, like insulin, GH can stimulate phosphorylation of She (9-11), an adaptor protein that interacts with the growth factor receptor and son of sevenless proteins and activates the Ras-Raf-MAPK signaling pathway. GH has also been shown to activate the S6 
kinase, $\mathrm{p} 90^{\mathrm{RSK}}$, most likely through MAPK (12). Thus, the fact that both IR and GHR use some of the same signaling molecules might partly explain the anti-insulin effect of GH. Another mechanism by which GH can reduce insulin sensitivity is by increasing the protein levels of suppressors of cytokine signaling (SOCS). Expression of SOCS-1, -3 , and -6 has been shown to have effects on insulin-induced IRS-1-p85 interactions and on activation of MAPK and AKT (13-17). Recently, it has been demonstrated that SOCS- 1 and -3 can bind IRS- 1 and -2 and promote their subsequent ubiquitination and degradation (18). Additionally, SOCS-1-deficient mice demonstrate a state of enhanced insulin sensitivity, resulting in a prolonged IRS-1 phosphorylation following insulin treatment (19). In contrast, adenoviral-driven expression of SOCS-1 in the liver of mice leads to a dramatic decrease in IRS-1 and -2 levels, leading to hyperglycemia, hyperinsulinemia, and insulin resistance (18). Recently, it has been shown that SOCS-6 has a binding site for IRS- 2 and -4 , and when expressed ectopically together with the IR, it inhibits the signal transduction through this receptor and can directly inhibit the kinase activity of the $\operatorname{IR}(14,20)$.

In a previous study, we used the liver IGF-1-deficient (LID) mouse model to understand the role of circulating IGF-1 in carbohydrate metabolism (21). LID mice have low circulating levels of IGF-1 and therefore exhibit increased GH secretion. At the age of 8-10 weeks, LID mice showed increased insulin secretion, impaired insulin tolerance, and an insensitivity to insulin in muscle at the level of phosphorylation of the IR and postreceptor substrates (21). Treatment of LID mice with exogenous IGF-1 (in superphysiological concentrations) for 4 weeks inhibited the secretion of GH and insulin and improved insulin sensitivity. Similarly, inhibition of GH secretion by treating LID mice with a GH-releasing hormone receptor antagonist for 4 weeks improved insulin sensitivity, though it did not return to normal levels (21). Our conclusion from these findings was that IGF-1 plays an important role in maintaining a fine balance between GH and insulin and thereby in maintaining normal carbohydrate metabolism. The previous findings, however, did not allow us to clearly determine whether low levels of circulating IGF-1 or increased levels of GH caused insensitivity in the LID mice. The present study was designed to answer this question.

We have now crossed LID mice with GH antagonist (GHa) transgenic mice to inactivate GH in the LID mice. GHa was generated by introducing a point mutation within the $\alpha$-helix III of the hormone, which prevents proper dimerization of the GHR and thereby blocks GH action (22). GHa transgenic mice are dwarfs and demonstrate a marked reduction in circulating IGF-1 levels (22). Expression of the GHa transgene in LID mice (LID + GHa) caused a marked reduction in blood glucose and insulin levels, an increased peripheral insulin sensitivity as measured by an insulin tolerance test, and a significant increase in insulin-stimulated glucose uptake in liver, muscle, and white adipose tissue (WAT), as measured by hyperinsulinemic-euglycemic clamp analysis.

\section{Methods}

Animal busbandry and genotyping. The generation and genotyping of LID (with a mixed genetic background of FVB/N, C57 Black, and 129Sv) (23) and GHa mice (C57B/6J) (22) has been described previously. LID and GHa mice were crossed to create LID + GHa transgenic mice. The Animal Care and Use Committee of the National Institute of Diabetes and Digestive and Kidney Diseases, National Institutes of Health (Bethesda, Maryland, USA) approved all procedures.

Animal crossing strategy for generation of LID + GHa mice. To generate the LID + GHa mice, three different gene modifications were required: the homozygous Igf-1 floxed allele, the GHa transgene, and the cre transgene under the albumin-enhancer promoter sequence (Alb-Cre). LID mice, which are homozygous for the Iff- 1 floxed allele and carry the Alb-cre transgene, were crossed with the GHa transgenic mice. Crossing of the $\mathrm{F}_{2}$ generation (which originated from breeding of $\mathrm{F}_{1}$ ) gave rise to four different genotypes within the same litter: (a) control mice, which are homozygous for the Igf-1 floxed allele; (b) LID mice, which are homozygous for the Iff-1 floxed allele and carry the Alb-cre transgene; (c) GHa mice, which are homozygous for the Igf-1 floxed allele and carry the GHa transgene; and (d) LID + GHa mice, which are homozygous for the Igf- 1 floxed allele and carry the Alb-cre and the GHa transgenes. These four genotypes represent the mice that were used throughout this study.

Determination of serum insulin, leptin, Cpeptide, TGs, and free FAs. Blood was collected from the retro-orbital sinus of 16- to 18-week-old male mice. Serum insulin levels (SRI-13K; Linco Research Inc., St. Charles, Missouri, USA), leptin (ML-82K; Linco Research Inc.), C peptide (RCP-21K; Linco Research Inc.), free fatty acids (FAs) (1383175; Roche Diagnostics, Basel, Switzerland), and TGs (339-11; Sigma-Aldrich, St. Louis, Missouri, USA) were measured using commercial kits, according to the manufacturers' recommended protocols.

Determination of body fat content. To assess body composition (percentage of fat), we performed whole-body measurements of intact mice using dual-energy $\mathrm{x}$-ray absorptiometry (PIXImus; GE-Lunar Corp., Madison, Wisconsin, USA). We evaluated fat, lean, and mineral mass, excluding the head and tail. Results are presented as fat content in percentage of total body weight (percentage of fat). In our laboratory the short-term precision error for whole-body measurements is less than $2 \%$.

Tissue TGs assay. Tissue TGs were extracted with chloroform/methanol as described by Burant et al. (24). After hydrolysis with $\mathrm{KOH}$ base, TGs were measured radiometrically using a glycerol kinase assay (25).

Insulin tolerance test. Male mice (12-16 weeks of age) were anesthetized with pentobarbital ( $45 \mu \mathrm{g} / \mathrm{g}$ body weight) and maintained on a heating pad for the duration of the procedure. Insulin tolerance tests were performed on fed animals at noon time (lights were on 12-hour dark/ 

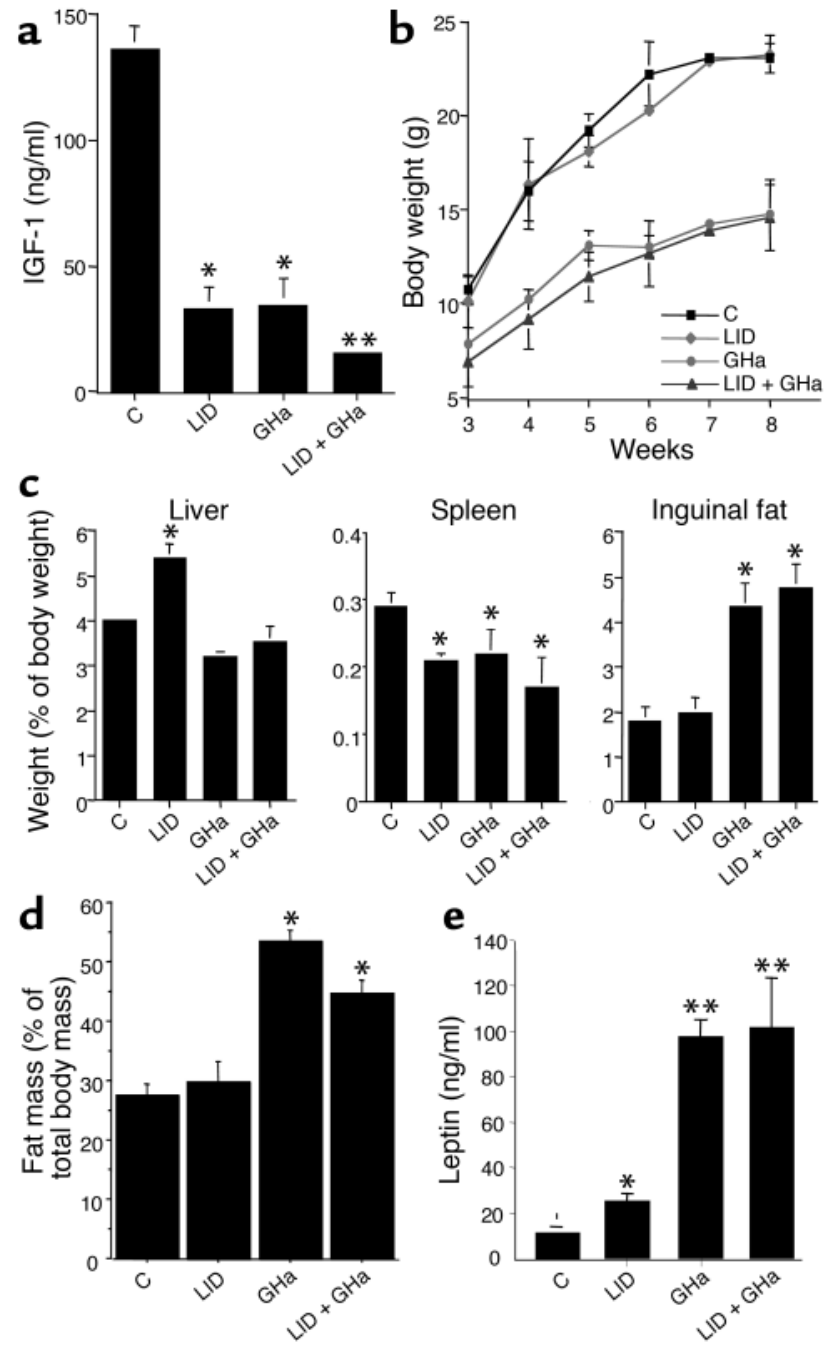

Figure 1

Comparison of IGF-1 levels, body weight, and organ weight in control (C), LID, GHa, and LID + GHa mice. (a) Serum was obtained as described in Methods and treated with acid-ethanol to remove IGFBPs. Total IGF-1 levels were determined by RIA in serum samples from control mice $(n=15)$, LID mice $(n=21)$, GHa mice $(n=12)$, and LID + GHa mice $(n=14) .{ }^{*} P<0.01$ compared with control mice; ${ }^{*} P<0.01$ compared with LID or GHa mice. (b) Body weight was measured at weekly intervals from birth to the age of 12 weeks ( $n=15-30$ mice per group). (c) Organ weight was measured at 16-18 weeks of age and is expressed as the average percentage of body weight. Data are expressed as average \pm SE. (d) Total body fat content was measured using dual-energy $x$-ray absorptiometry analysis of at least five mice per group. Data are expressed as average \pm SE. ${ }^{*} P<0.01$ compared with control mice. (e) Serum leptin was determined by RIA in serum samples from control mice $(n=8)$, LID mice $(n=8)$, GHa mice $(n=10)$, and LID + GHa mice $(n=8) .{ }^{*} P<0.01$ compared with control mice; ${ }^{*} P<0.01$ compared with LID mice.

12-hour light cycle). Human insulin (Sigma-Aldrich) was injected intraperitoneally at time point $0(0.5 \mathrm{IU} / \mathrm{kg})$. Blood was drawn from the tail vein at the indicated time points, and glucose levels were measured using a glucometer (Surestep; Lifescan Inc., Milpitas, California, USA).

Hyperinsulinemic-englycemic clamp. The hyperinsulinemic-euglycemic clamp protocol is based on one devel- oped by Jason Kim and Gerald Shulman (26). Mice were anesthetized with $100 \mathrm{mg} / \mathrm{kg}$ ketamine and 10 $\mathrm{mg} / \mathrm{kg}$ xylazine. A catheter was inserted through a right lateral neck incision, advanced into the superior vena cava through the right internal jugular vein, and sutured in place, according to the protocol of MacLeod and Shapiro (27). Clamp studies were performed on fasted male mice 16-18 weeks of age between 4 and 6 days after catheter insertion.

In vivo insulin stimulation. Experiments were carried out in 16-week-old male mice fasted overnight. Animals were anesthetized with $150 \mu \mathrm{l}$ of avertin $2.5 \%$ followed by injection with human insulin (5 IU insulin) through the inferior vena cava. Hindlimb muscle was removed 1 minute after injection and homogenized in homogenization buffer $(10 \mathrm{mM}$ Tris, $\mathrm{pH} 7.6,1 \%$ Triton X-100, $0.5 \%$ Nonidet P-40, $150 \mathrm{mM} \mathrm{NaCl}, 10 \mathrm{mM}$ sodium orthovanadate, $10 \mathrm{mM}$ sodium pyrophosphate, $100 \mathrm{mM}$ sodium fluoride, $1 \mathrm{mM}$ EDTA, 1 mM EGTA, and a cocktail of protease inhibitors; Boehringer Mannheim $\mathrm{GmbH}$, Mannheim, Germany). Samples were allowed to solubilize for 30 minutes on ice, and particulate matter was removed by centrifugation at $40,000 \mathrm{~g}$ for 1 hour at $4^{\circ} \mathrm{C}$ in a Beckman Ti-70 rotor. Two milligrams of tissue extracts were immunoprecipitated with anti-IR- $\beta$ subunit, anti-AKT (Santa Cruz Biotechnology Inc., Santa Cruz, California, USA), and anti-IRS-1 (Upstate Biotechnology Inc., Lake Placid, New York, USA) Ab's. Immunoprecipitated samples were subjected to SDS-PAGE and Western blotting. Blots were probed with an anti-phosphotyrosine $\mathrm{Ab}$ (RC20; Transduction Laboratories Inc., Lexington, Kentucky, USA) and anti-phospho-AKT (Santa Cruz Biotechnology Inc.), and signals were detected by enhanced chemiluminescence. Blots were then stripped and reprobed with the above Ab's for detection of total protein levels. Signals were scanned and band intensities were quantified by optical densitometry of the developed autoradiograms.

Determination of gene expression. Tissues were homogenized with a polytron homogenizer (Brinkmann Instruments Inc., Westbury, New York, USA) in RNazol B reagent (Tel-Test Inc., Friendswood, Texas, USA), and total RNA was isolated according to the manufacturer's instructions. Total RNA $(50 \mu \mathrm{g})$ was run on $0.8 \%$ agarose gel and transferred to nitrocellulose. Prehybridization and hybridization were carried out at $42^{\circ} \mathrm{C}$ with ${ }^{32} \mathrm{P}$-labeled probes corresponding to glucose-6 phosphatase (G6Pase), phosphenolpyruvate carboxy kinase (PEPCK), glycogen synthase, PPAR $\alpha$, acetyl-CoA carboxylase (ACC), CD36lipoprotein, and carnitine palmitoyltransferase I (CPTI), which were obtained as described previously (28), and mouse 18S mRNA (Ambion Inc., Austin, Texas, USA). The leptin probe was kindly provided by Sunhee Yim (National Cancer Institute, Bethesda, Maryland, USA).

Statistical analysis. Statistical analyses were performed using Statview 4.5 software (SAS Institute Inc., Cary, North Carolina, USA). Unpaired Student $t$ tests were used to compare hormone levels between the various groups. All values are reported as the mean plus or 
minus SEM, and differences were considered to be statistically significant at $P$ values less than 0.05 .

\section{Results}

Introduction of the GHa transgene affects serum IGF-1 levels, body weight, and organ weight. As reported previously (23), LID mice showed a $75 \%$ reduction in circulating IGF-1 levels $(34.3 \pm 7.5 \mathrm{ng} / \mathrm{ml}, P<0.05)$ (Figure 1a). Similarly, the GHa transgenic mice showed $74 \%$ reduction in circulating IGF-1 levels $(35.7 \pm 9.29 \mathrm{ng} / \mathrm{ml}, P<0.05)$, as compared with control mice $(137 \pm 8.3 \mathrm{ng} / \mathrm{ml})$. The LID + GHa mice, however, exhibited a larger $(88 \%)$ decrease in circulating IGF-1 levels $(16.3 \pm 0.57 \mathrm{ng} / \mathrm{ml}, P<0.001$, as compared with controls, and $P=0.04$, as compared with GHa or LID mice). These results suggest that the GHa transgene inhibited the secretion of nonhepatic IGF-1 into the circulation and/or caused a reduction in $\mathrm{GH}$-dependent proteins required for stabilization of IGF-1 in circulation (IGFBP-3 and ALS).

Consistent with our findings from previous studies (23), the body weight of LID mice did not differ significantly from that of control mice, despite the dramatic reduction in serum IGF-1 levels. In contrast, the body weight of GHa and LID + GHa mice was significantly decreased, as compared with control and LID mice between the ages of 3 and 8 weeks $(P<0.001$; Figure $1 \mathrm{~b})$ (this growth retardation is seen as early as 2 weeks of age). As shown in Figure 1c, the weight of the inguinal fat pads in control and LID mice was $1.8 \% \pm 0.3 \%$ and $1.9 \% \pm 0.3 \%$ of body weight at the age of 16-18 weeks, respectively. GHa and LID + GHa mice, however, exhibited twofold increase in inguinal fat pad weight $(4.36 \% \pm 0.52 \%$ and $4.79 \% \pm 0.5 \%$ of body weight, respectively; $P<0.001$ ). Body fat content was also determined by using dual-energy $\mathrm{x}$-ray absorptiometry (PIXImus) of intact mice. As shown in Figure 1d, body fat content was increased about twofold in the GHa and LID + GHa mice, as compared with control mice $(P<0.0001)$. As shown in Figure 1e, serum leptin levels were increased tenfold in the GHa and LID + GHa mice as expected due to increased body fat content. Leptin mRNA expression in fat tissue was similarly increased fivefold in the GHa and LID + GHa mice (data not shown). A twofold increase in serum leptin levels was observed in the LID mice, and leptin mRNA expression in the WAT was similarly increased twofold (data not shown). Liver weight at 16-18 weeks was significantly higher in LID mice $(5.4 \% \pm 0.3 \%$ of body weight, $P=0.04$ ), presumably due to the long-term increase in GH levels, as compared with control mice $(4.0 \% \pm 0.03 \%$ of body weight). No significant difference in liver weight was observed in $\mathrm{GHa}(3.22 \% \pm 0.1 \%$ of body weight) or LID + GHa mice ( $3.5 \% \pm 0.3 \%$ of body weight), as compared with controls, however, though they tend to be smaller. As reported previously (23), spleen weight was markedly decreased in LID mice $(0.21 \% \pm 0.01 \%$ of body weight, $P<0.05)$. Spleen weight was similarly decreased in $\mathrm{GHa}(0.22 \% \pm 0.03 \%$ of body weight, $P<0.05)$ and LID + GHa mice $(0.17 \% \pm 0.04 \%$ of body weight, $P<0.05)$, as compared with control mice $(0.29 \% \pm 0.02 \%$ of body weight), most likely due to the marked decrease in circulating levels of IGF-1 in all three genotypes.

Metabolic parameters in control and genetically modified mice. Blood glucose levels in the fasting state did not differ between control and LID mice $(149.7 \mathrm{mg} / \mathrm{dl}$ and $152.0 \mathrm{mg} / \mathrm{dl}$, respectively), as shown in Figure 2a. The lack of GH action in the GHa and LID + GHa mice, however, resulted in a dramatic reduction in blood glucose levels in these genotypes $(75.4 \mathrm{mg} / \mathrm{dl}$ and $58.0 \mathrm{mg} / \mathrm{dl}$, respectively; $P<0.001$, as compared with controls) (Figure 2a). Serum insulin levels in LID mice were elevated approximately twofold $(2.5 \mathrm{ng} / \mathrm{ml}, P<0.05)$ as compared with control mice $(1.4 \mathrm{ng} / \mathrm{ml}$ ) (Figure $2 \mathrm{~b}$ ), which is consistent with findings from our previous study (21). In contrast, GHa and LID + GHa mice exhibited significantly lower levels of serum insulin $(0.33 \mathrm{ng} / \mathrm{ml}$ and 0.69 $\mathrm{ng} / \mathrm{ml}$, respectively; $P<0.05)$. As we demonstrated previously (21), LID mice have $\beta$ cell hyperplasia, probably as compensation for the insulin insensitivity in those mice. Introducing the GHa transgene, which increased insulin sensitivity, was not associated with a decrease in islet mass in the LID + GHa mice (data not shown). C peptide levels were increased in LID $(710 \pm 132 \mathrm{ng} / \mathrm{ml})$ and LID $+\mathrm{GHa}(740 \pm 192 \mathrm{ng} / \mathrm{ml})$ mice, as compared with con-
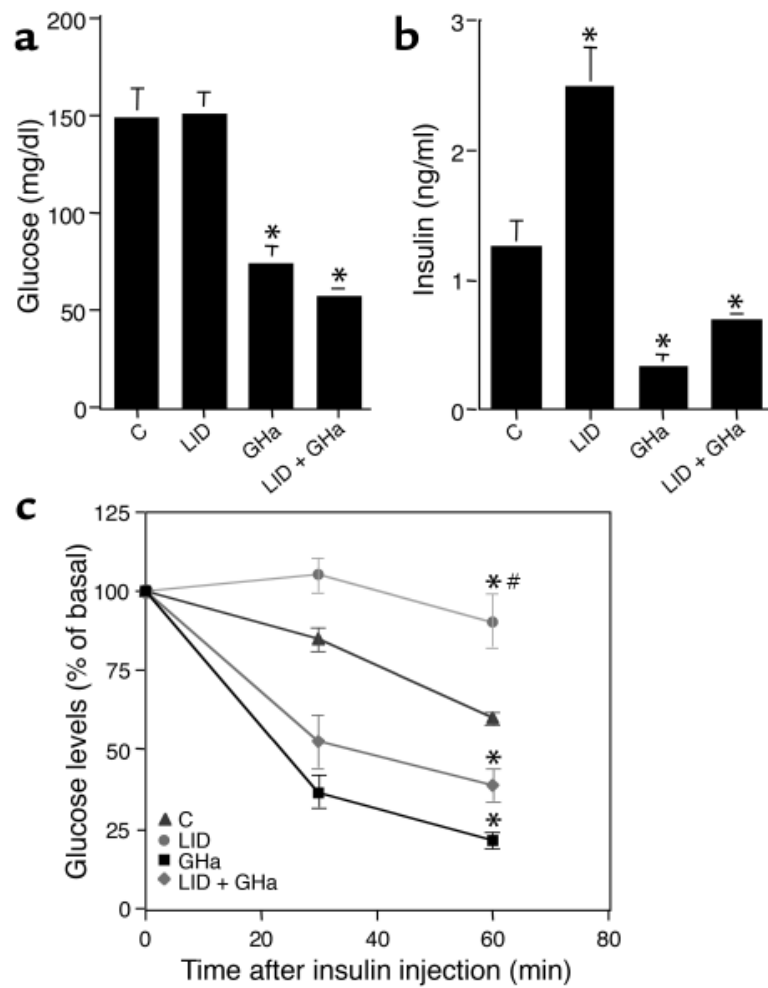

\section{Figure 2}

LID mice expressing the GHa transgene exhibit enhanced insulin sensitivity. (a) Blood glucose levels were measured in the fed state in control, LID, GHa, and LID + GHa mice. (b) Serum insulin levels were measured in the fed state in the four genotypes. (c) Insulin tolerance tests were performed on the four genotypes of mice, as described in Methods. Results are expressed as the mean percentage of basal blood glucose concentration \pm SEM. ( ${ }^{*} P<0.05$ compared with control; ${ }^{\#} P<0.05$ compared with GHa.) 

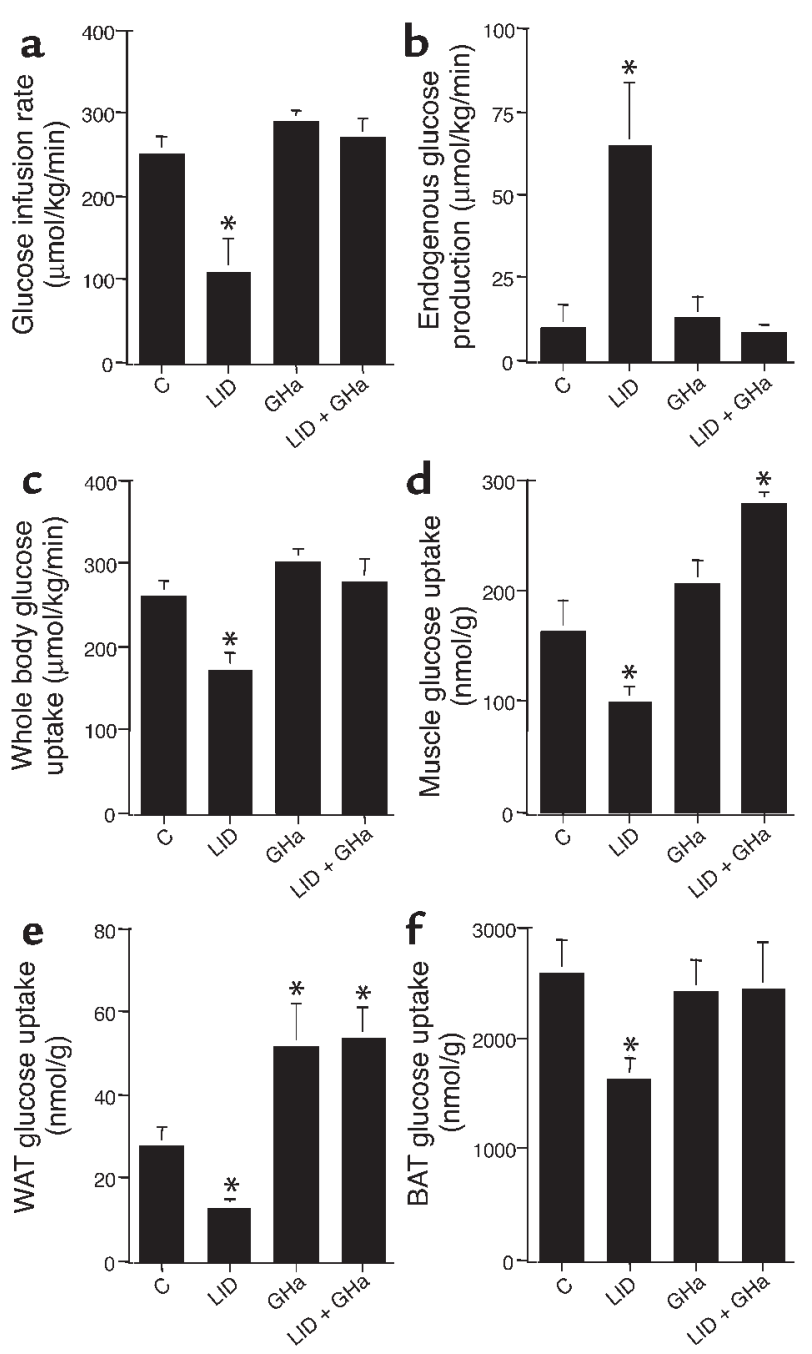

trol mice $(322 \pm 53 \mathrm{ng} / \mathrm{ml})$. It was reported previously that leptin receptors are expressed in the insulin-producing $\beta$ cells within the pancreas (29), and in the presence of low-glucose concentrations, as seen in the GHa and LID + GHa mice, leptin increased insulin secretion by perfused isolated islets $(30,31)$. In contrast to the LID mice, however, which have high levels of serum insulin and C peptide, LID + GHa mice have reduced insulin levels, suggesting that insulin is cleared more efficiently by the LID + GHa mice. These data suggest that GHa expression induced a state of relative GH deficiency, which leads to increased insulin sensitivity and therefore enhanced insulin extraction by the liver, over and above that seen in control animals.

Insulin tolerance tests were carried out on randomly fed control, LID, GHa, and LID + GHa mice at 10-12 weeks of age (Figure 2c). As shown in our previous study (21), the LID mice exhibited a state of insulin insensitivity and were unable to clear blood glucose 60 minutes after the insulin injec-

\section{Figure 3}

Various metabolic parameters during hyperinsulinemic-euglycemic clamp of control, LID, GHa, and LID + GHa mice. (a) Average glucose infusion rates were measured during 90-120 minutes of the hyperinsulinemic-euglycemic clamp. (b) Insulin-stimulated hepatic glucose production during the hyperinsulinemic-euglycemic clamp. (c) Insulinstimulated whole-body glucose uptake. (d) Insulin-stimulated muscle (gastrocnemius) glucose uptake. (e) Insulin-stimulated WAT glucose uptake. (f) Insulin-stimulated BAT glucose uptake. Data are expressed as average \pm SE for $n=6$ animals per group. $\left({ }^{*} P<0.05\right.$ compared with control.)

tion. When the GHa transgene was expressed in LID mice (LID + GHa), however, they became insulin sensitive and were able to efficiently clear glucose to $40 \%$ of basal levels after the insulin injection. Thus, the insulin sensitivity of LID + GHa mice resembled that of GHa mice, which were able to clear glucose to $25 \%$ of basal levels after the insulin injection. Glucose values did not differ significantly between GHa and LID + GHa mice 60 minutes after insulin injection.

Total body insulin sensitivity measured by hyperinsulinemicenglycemic clamp. Insulin action on glucose transport and metabolism was examined during a 2-hour hyperinsulinemic-euglycemic clamp in awake control, LID, GHa, and LID + GHa mice at 16-18 weeks of age (Figure 3, Table 1). Basal plasma insulin concentrations during the clamp did not differ significantly between the groups (data not shown). During the clamp, plasma insulin levels were infused at a rate of $15 \mathrm{pM} / \mathrm{kg} / \mathrm{min}$, while the goal was to maintain glucose levels at $140 \mathrm{mg} / \mathrm{dl}$ by a variable infusion of glucose in all the groups. The glucose infusion rate required to maintain euglycemia reached a steady state after 90 minutes in control mice $(252 \pm 21 \mu \mathrm{mol} / \mathrm{kg} / \mathrm{min})$. Impaired insulin responsiveness in the LID mice during the hyperinsulinemic-euglycemic clamp was reflected by a lower steady-state glucose infusion rate $(109 \pm 39 \mu \mathrm{mol} / \mathrm{kg} / \mathrm{min} ; P<0.05)$ (Figure 3a). When GH action was inhibited by expression of the GHa transgene in the LID + GHa and GHa mice, however, the glucose infusion rate was similar to that of the control group $(291 \pm 12 \mu \mathrm{mol} / \mathrm{kg} / \mathrm{min}$ and $271 \pm 22$ $\mu \mathrm{mol} / \mathrm{kg} / \mathrm{min}$, respectively). The ability of insulin to suppress hepatic glucose production during the hyperinsu-

\section{Table 1}

Various metabolic parameters during basal and hyperinsulinemic-euglycemic clamping in control, LID, GHa, and GHa + LID mice

\begin{tabular}{lcccc}
\hline & C & LID & GHa & LID + GHa \\
Body weight at $16-18 \mathrm{wk}(\mathrm{g})$ & $19.3 \pm 0.4$ & $24.1 \pm 1.5$ & $14.4 \pm 0.6^{\mathrm{A}}$ & $13.6 \pm 1.4^{\mathrm{A}}$ \\
Basal glucose $(\mathrm{mg} / \mathrm{dl})$ & $148.5 \pm 7.2$ & $176.7 \pm 16.6^{\mathrm{A}}$ & $125 \pm 12.9$ & $103 \pm 10.6$ \\
Basal EGP $(\mu \mathrm{mol} / \mathrm{kg} / \mathrm{min})$ & $115.5 \pm 16.9$ & $88.5 \pm 4.3$ & $72.4 \pm 4.9$ & $94 \pm 2.5$ \\
$\begin{array}{l}\text { Clamp-WB glycolysis } \\
(\mu \mathrm{mol} / \mathrm{kg} / \mathrm{min})\end{array}$ & $209.5 \pm 13.0$ & $146.5 \pm 12.3^{\mathrm{A}}$ & $204.4 \pm 17.5$ & $206.3 \pm 35.0$ \\
$\begin{array}{l}\text { Clamp-WB glycogen } \\
\text { synthesis }(\mu \mathrm{mol} / \mathrm{kg} / \mathrm{min})\end{array}$ & $52.7 \pm 13.7$ & $28 \pm 16.1^{\mathrm{A}}$ & $100.2 \pm 13.5^{\mathrm{A}}$ & $74.3 \pm 20.1^{\mathrm{A}}$ \\
Clamp glucose $(\mathrm{mg} / \mathrm{dl})$ & $117 \pm 1.6$ & $133.7 \pm 13.9$ & $128.2 \pm 9.2$ & $121.3 \pm 4.0$
\end{tabular}

$A P<0.05$ versus control group by unpaired Student's $t$ test. C, control; EGP, endogenous glucose production; WB, whole body. 

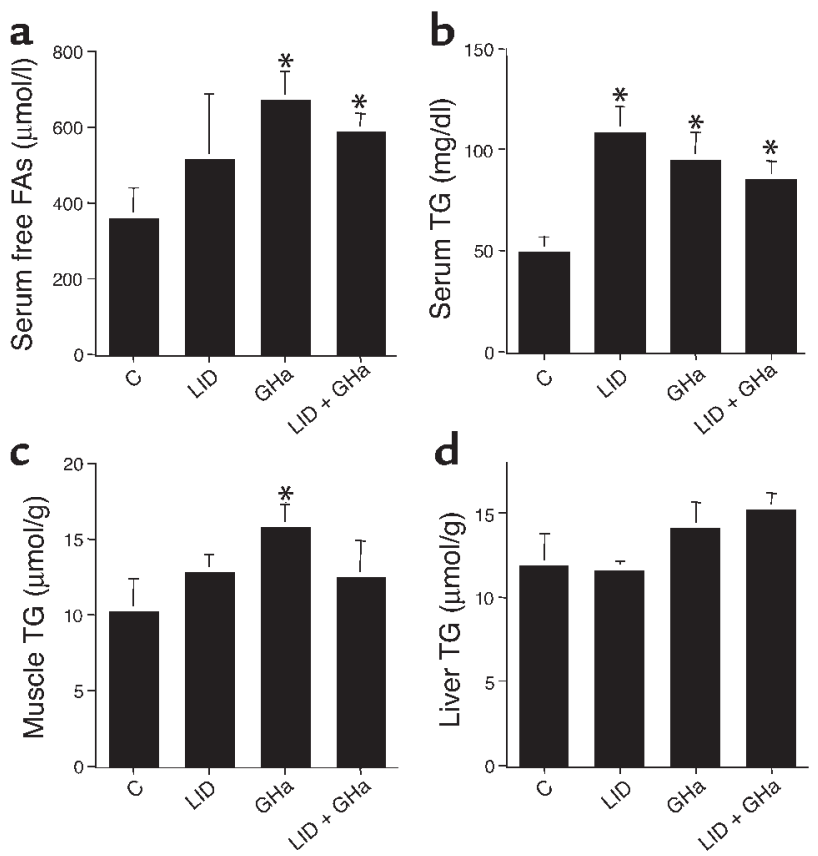

linemic-euglycemic clamping was severely impaired in the LID mice $(65 \pm 19 \mu \mathrm{mol} / \mathrm{kg} / \mathrm{min} ; P<0.05)$, as compared with control mice $(10 \pm 7 \mu \mathrm{mol} / \mathrm{kg} / \mathrm{min})$ (Figure $3 \mathrm{~b}$ ). Transgenic expression of GHa in the LID + GHa mice reversed this phenotype, however, and resulted in a marked decrease in hepatic glucose production during the clamp in GHa and LID + GHa mice $(12 \pm 6 \mu \mathrm{mol} / \mathrm{kg} / \mathrm{min}$ and $9 \pm 2 \mu \mathrm{mol} / \mathrm{kg} / \mathrm{min}$, respectively). Insulin-stimulated whole body glucose uptake was decreased $30 \%$ in the LID mice $(P<0.05)$, but was similar to control levels when the GHa transgene was expressed (Figure 3c). Insulin-stimulated glycolysis and glycogen synthesis were significantly decreased in LID mice $(P<0.05)$, as shown in Table 1 .

Insulin-stimulated glucose transport in skeletal muscle, WAT, and brown adipose tissue (BAT), was estimated by determining the 2-deoxy- $\mathrm{D}\left[{ }^{14} \mathrm{C}\right]$-glucose content in those tissues after administration of a bolus $(10 \mu \mathrm{Ci}) 45$ minutes before the end of the clamp. Insulin-stimulated glucose transport activity in muscle (gastrocnemius) of

\section{Figure 5}

Inactivation of insulin action in the LID mice is restored by introduction of $\mathrm{GHa}$ ( $\mathrm{LID}+\mathrm{GHa}$ mice). (a) A Western blot analysis of insulininduced phosphorylation of the IR (b), IRS-1 (c), and AKT (d) in muscle. The levels of phosphorylation signals $(P)$ are normalized to total immunoreactivity of IR, IGF-1R, or IRS- 1 of $n=4$ in each group. $\left({ }^{*} P<0.05\right.$ compared with unstimulated samples.) $\mathrm{AU}$, arbitrary units.

\section{Figure 4}

Fasting concentrations of FAs and TG in serum of control, LID, GHa, and LID + GHa mice. (a) Serum FA levels were measured in the various genotypes ( $n=6$ mice per group). (b) TG levels were measured in the various genotypes ( $n=6$ mice per group). (c) Muscle TG content. (d) Liver TG content. ( ${ }^{*} P<0.05$ compared with control.)

LID mice was decreased $40 \%(P<0.05)$, as compared with controls $(100 \pm 14 \mathrm{nmol} / \mathrm{g}$ of muscle per minute and $164 \pm 27 \mathrm{nmol} / \mathrm{g}$ of muscle per minute, respectively) (Figure 3d). Expression of the GHa transgene in LID + GHa mice significantly increased muscle glucose uptake ( $280 \pm 10 \mathrm{nmol} / \mathrm{g}$ of muscle per minute), however. Similarly, glucose uptake in WAT was reduced $50 \%(P<0.05)$ in the LID mice, as compared with controls, but was increased twofold when the GHa was expressed in LID + GHa and GHa mice (Figure 3e). Glucose uptake in the BAT was reduced $40 \%(P<0.05)$ in the LID mice, as compared with controls, but was similar to control levels in LID + GHa and GHa mice (Figure 3f).

Serum-free FAs and tissue TGs. As described above, GHa and LID + GHa mice exhibited a twofold increase in fat pad mass. To understand the potential implications of increased adiposity on glucose metabolism, we measured free FAs and TGs in serum as well TG content in tissue. Figure 4a shows serum FA levels in control, LID, GHa, and LID + GHa mice. Serum FA levels were significantly higher in GHa $(673 \pm 75 \mu \mathrm{mol} / \mathrm{l})$ and LID + GHa mice $(592 \pm 44 \mu \mathrm{mol} / \mathrm{l})$, as compared with controls $(P<0.05)$. There was a slight tendency for serum FA levels to be increased in LID mice $(518 \pm 169 \mu \mathrm{mol} / \mathrm{l})$, as compared
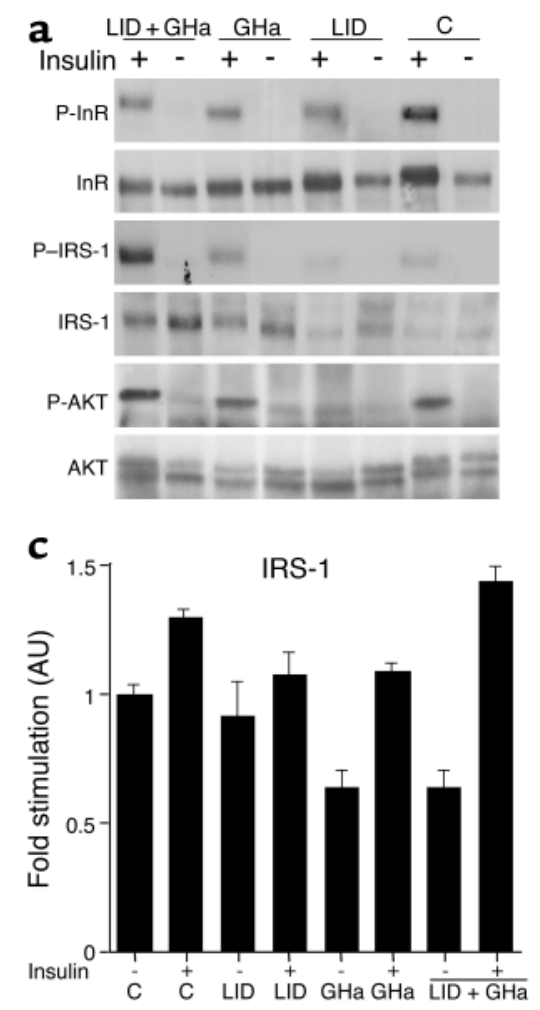

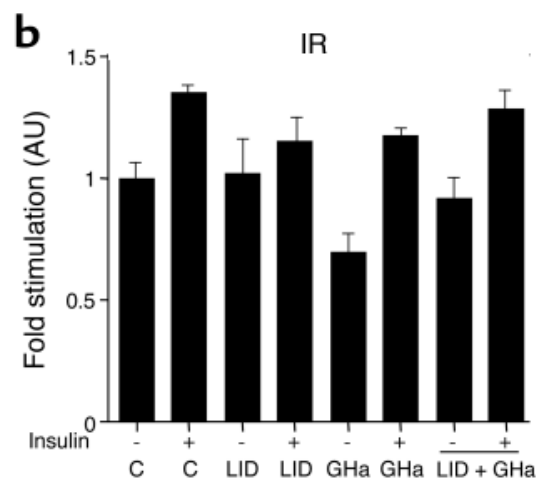

d

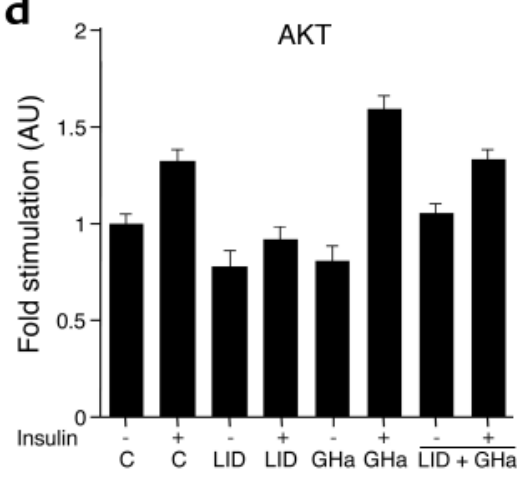



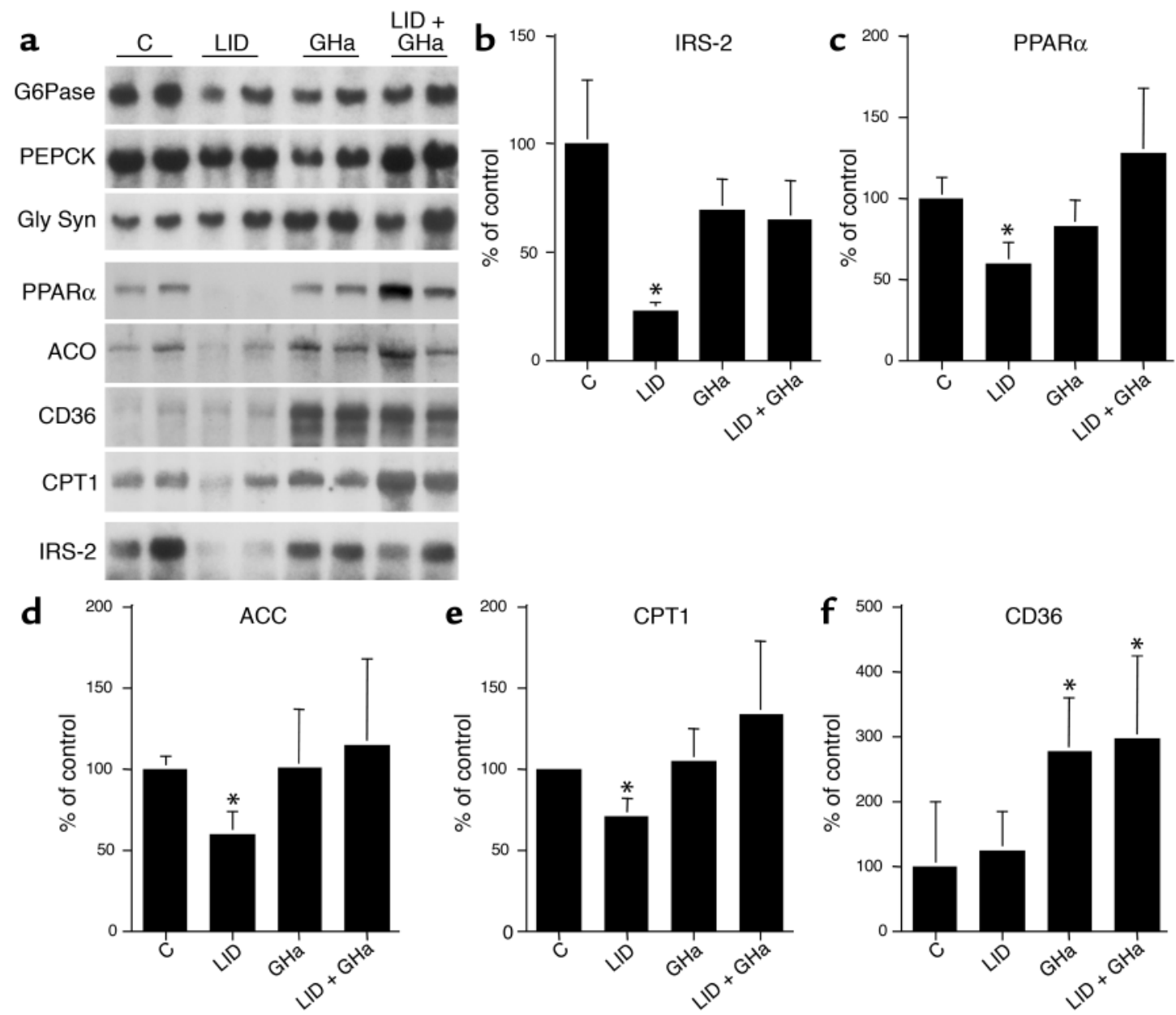

\section{Figure 6}

Analysis of mRNA levels of various genes related to glucose metabolism, lipid metabolism, and insulin signaling in livers of control, LID, GHa, and LID + GHa mice (5-6 mice per group). (a) Northern blots were used to measure G6Pase, PEPCK, glycogen synthase (Gly Syn), PPAR $\alpha$, ACO, CD36, CPTI, and IRS-2 mRNA levels. Average values for the mRNA levels of IRS-2 (b), PPAR $\alpha$ (c), ACC (d), CPT1 (e), and CD36 (f) that differed between genotypes are shown in the graphs. Data are expressed as average \pm SE for four animals per group, normalized to $18 \mathrm{~S}$ RNA levels. ( $P<0.05$ compared with control.)

with controls $(363 \pm 77 \mu \mathrm{mol} / \mathrm{l})$, but this difference did not achieve statistical significance. Serum TG levels were significantly elevated in all groups $(109 \pm 12 \mathrm{mg} / \mathrm{dl}$ in LID, $96 \pm 12.1 \mathrm{mg} / \mathrm{dl}$ in GHa, and $86 \pm 8.5 \mathrm{mg} / \mathrm{dl}$ in LID + GHa mice; $P<0.05)$, as compared with control mice $(50 \pm 6.3 \mathrm{mg} / \mathrm{dl}$; Figure $4 \mathrm{~b})$. The TG content of muscle and liver, however, did not differ significantly between the groups except for the TG content in the muscles of GHa mice, which could be a result of intramuscular fat (Figure 4, $c$ and d).

Early signaling events after in vivo insulin stimulation. The early signaling events after insulin stimulation in skeletal muscle were compared between control, LID, GHa, and LID + GHa mice. As shown in Figure 5, insulin stimulated $30-40 \%$ increase $(P<0.05)$ in tyrosine phosphorylation of the IR in muscle of control, GHa, and LID + GHa mice; however, it failed to stimulate tyrosine phosphorylation of the IR in the muscles of LID mice (Figure 5, a and b). Similarly, insulin stimulated tyrosine phosphorylation of IRS-1 30-55\% in muscle samples from control, GHa, and
LID + GHa mice; however, it failed to stimulate tyrosine phosphorylation of the IRS-1 in muscle of LID mice (Figure 5, a and c). AKT phosphorylation in muscle of control, GHa, and LID + GHa mice was increased $25-50 \%$; however, there was no effect of insulin-induced AKT phosphorylation in skeletal muscle from LID mice (Figure 5, a and d). Taken together, these studies show that tyrosine phosphorylation of the IR and IRS- 1 and AKT phosphorylation in response to insulin stimulation is virtually abolished in the muscle of LID mice. When GH action is inhibited in the LID + GHa mice, however, the phosphorylation of the IR, IRS-1, and AKT in response to insulin stimulation is restored.

Gene expression of key regulators of insulin action and glucose metabolism in liver. In view of the increased insulin sensitivity and adiposity in GHa and LID + GHa mice, we next measured mRNA levels of various key regulators of insulin action and lipid metabolism. In liver, the expression of enzymes involved in glucose metabolism, such as G6Pase, PEPCK, and glycogen synthase, did not differ sig- 
nificantly between the groups (Figure 6). In contrast, there was a marked reduction in IRS- 2 mRNA levels in the liver of LID mice. IRS-2 is an essential component of the insulin-signaling pathway, and its downregulation presumably results from the chronic elevations in insulin levels in LID mice (32) (Figure 6a). Mice expressing the GHa transgene (GHa and LID + GHa mice) have low levels of insulin, however, and exhibit IRS-2 mRNA levels similar to those found in control mice. PPAR $\alpha$ has been shown to play a critical role in the regulation of cellular uptake, activation, and $\beta$ oxidation of free FA. As shown in Figure 6b, LID mice, which have high levels of GH, exhibit markedly lower levels of PPAR $\alpha$ mRNA expression in the liver. In contrast, inhibition of $\mathrm{GH}$ action by introducing GHa into the LID mice (LID + GHa mice) and in GHa mice alone led to a return to control levels in PPAR $\alpha$ mRNA. Additionally, the expression level of several target genes of PPAR $\alpha$, including ACC, the CD36lipoprotein receptor/FA transporter, and CPTI were restored to control levels in LID + GHa mice (Figure 6, $\mathrm{c}-\mathrm{e})$, presumably as a result of increased PPAR $\alpha$ activity.

\section{Discussion}

$\mathrm{GH}$ exerts a variety of metabolic effects either directly or indirectly on three insulin-sensitive organs: liver, muscle, and WAT. Studies in humans and animal models show that chronic excess GH has an anti-insulin effect on carbohydrate and lipid metabolism (3). The response to GH oversecretion is usually difficult to interpret, however, because of a concomitant increase in IGF-1 levels. Animal models of chronic elevations in GH secretion show increased serum IGF-1 levels, and GH-deficient patients treated with GH exhibit a similar increase in circulating IGF-1 levels (33). In our previous study with the LID mice, we were able to show that excess $\mathrm{GH}$ secretion was associated with insulin insensitivity in muscle (21). Because circulating IGF-1 levels were simultaneously reduced, however, we were unable to clearly determine whether the insulin resistance observed in LID mice resulted from elevated GH levels or from reduced IGF-1 levels. In the present study we blocked GH action in LID mice by crossing them with GHa transgenic mice. Inactivation of GH action in the LID + GHa mice led to a decrease in blood glucose levels, despite decreased insulin levels. These findings suggest that LID + GHa mice are in a state of enhanced insulin sensitivity. Peripheral insulin sensitivity, as measured by acute insulin administration in insulin tolerance tests, showed that blocking GH action in the LID + GHa mice improved insulin sensitivity, as compared with controls and LID mice. Similarly, hyperinsulinemic-euglycemic clamp analysis showed that LID mice exhibited severe insulin resistance, which could be attributed to defects in insulin action in liver muscle and WAT. Expression of the GHa transgene in the LID + GHa mice leads to normalization of insulin sensitivity, however, and resulted in an increased insulin-stimulated glucose uptake in muscle and WAT, as compared with control levels. The ability of insulin to inhibit hepatic glucose production during the clamp was impaired in the LID mice. When GH action was blocked (in LID + GHa mice), however, hepatic glucose production was suppressed to the levels observed in control mice. Here we demonstrate that despite low levels of circulating IGF-1, insulin sensitivity was improved by blocking $\mathrm{GH}$ secretion, suggesting that $\mathrm{GH}$ secretion causes the insulin insensitivity observed in LID mice. The mechanism whereby GH inhibits insulin action at the cellular level is not well understood. We show that insulin-induced IR and IRS-1 tyrosine phosphorylation and AKT serine phosphorylation were abolished in the LID mice, and inactivation of GH secretion by introducing GHa improved muscle responsiveness to insulin. The return to insulin responsiveness in postreceptor signaling follows the same pattern seen in the clamp studies with enhanced liver, fat, and muscle insulin sensitivities.

Association of GH deficiency with enhanced insulin sensitivity has been described in both human and animal models. Hypox animals and GH-deficient patients exhibit decreased fasting glucose levels, impaired glucose tolerance, decreased insulin levels, and increased insulin sensitivity $(6,34-39)$. A GH-deficient state is also characterized by decreased hepatic glucose production (38). The enhanced insulin sensitivity in GH deficiency is due both to increased glucose use and impaired hepatic glucose production in response to low glucose concentrations $(40,41)$. On the other hand, chronic administration of GH to hypox animals or to GH-deficient patients raised fasting glucose levels and further impaired the glucose tolerance despite increased levels of insulin (3). Furthermore, abnormal GH secretion in acromegalic patients lead to impaired intravenous and oral glucose disposal that is associated with hyperinsulinemia (42-46), impaired insulin-stimulated glucose uptake, and impaired suppression of hepatic glucose production during hyperinsulinemic-euglycemic clamping (47). It has also been shown that treatment of acromegalic patients with exogenous insulin did not improve muscle glucose uptake or decrease hepatic glucose output (48, 49). Thus, increased insulin secretion in those patients does not compensate for the increased insulin resistance, which is believed to be mediated through the GHR (50). Long-term studies of acromegalic patients show that

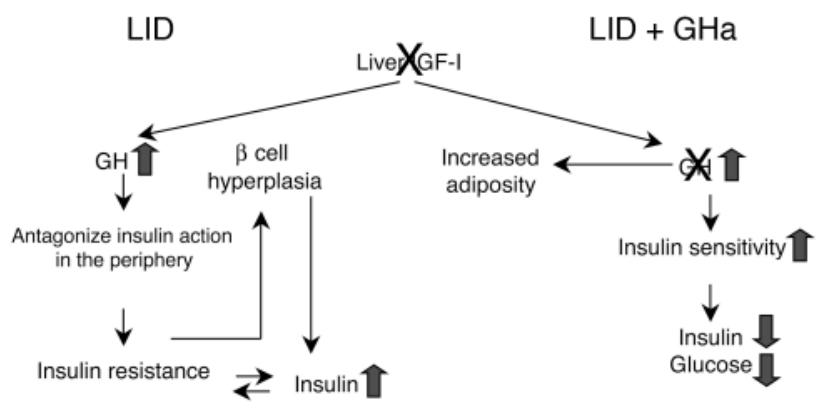

Figure 7

Schematic of the effects of excess $\mathrm{GH}$ and inactivation of GH in LID and LID + GHa mice. Inactivation of GH action in the face of low levels of IGF-1 increases insulin sensitivity, as discussed in the text. 
insulin sensitization is improved by treatment with agents that block $\mathrm{GH}$ secretion in a substantial number of patients $(51,52)$. In a recent study by O'Connell and Clemmons, a GHR antagonist was given to acromegalic patients for 6 months to block GH action (53). This study clearly demonstrated that GHR antagonist treatment significantly improved insulin sensitivity. Addition of IGF-1 in combination with the GHR antagonist resulted in substantially greater improvement in the insulin sensitivity, suggesting that IGF-1 exerts additional effects on insulin sensitivity that are not mediated through suppression of GH action (53).

$\mathrm{GH}$ plays a role in the regulation of lipolysis and lipogenesis, as well as in the differentiation of preadipocytes $(54,55)$. GH can promote lipolysis by stimulating the HSL, which is the rate-limiting step for release of stored TG from adipocytes $(56,57)$. Children and adults with GH deficiency exhibit markedly higher percentages of body fat and lower percentages of lean body mass. The excessive fat tissue is distributed in visceral and truncal areas $(58,59)$. When $\mathrm{GH}$-deficient subjects receive $\mathrm{GH}$ treatment, adipose tissue mass is significantly decreased, whereas fat oxidation, energy expenditure, and lean body mass are significantly increased (54). GH also stimulates hydrolysis of TG into glycerol and FA, stimulates FA transport to the liver, and inhibits the re-esterification of FA by adipocytes (57). In the present study, inactivation of GH action in the GHa and LID + GHa mice lead to increased fat mass (approximately twofold), most likely due to inhibition of lipolysis. Additionally, there was an increase in serum leptin levels and leptin mRNA expression in fat tissue in the LID, GHa, and LID + GHa mice. The effects of IGF-1 on serum leptin and leptin expression are contradictory. Studies in rats, however, show that administration of human IGF-1 decreased leptin mRNA in epididymal fat pads in normal rats and, as a consequence, reduced serum leptin $(60,61)$. Gene deletion of liver IGF-1 in the LID and LID + GHa mice leads to decreased levels of serum IGF-1 and therefore could cause an upregulation of leptin mRNA expression.

$\mathrm{GH}$ serves as a negative regulator of hepatic PPAR $\alpha$, which is a major regulator of lipid metabolism (62), and a number of studies have shown that GH treatment suppresses the expression of certain PPAR-inducible liver $\mathrm{P} 450$ genes in the rat (63-66). In rat primary hepatocytes, it was demonstrated that GH inhibited peroxisomal FA $\beta$ oxidation induced by PPAR $\alpha$ agonists (67). Activation of PPAR $\alpha$ causes upregulation of ACO (62), CD36lipoprotein receptor/FA transporter (68), and CPTI, which catalyzes the rate-limiting step in translocation of activated free FAs into the mitochondria (69). Excess activity of GH in the LID mice was associated with downregulation of PPAR $\alpha$ mRNA in the liver and a corresponding decrease in mRNA of the downstream enzyme ACO and FA transporters CD36 and CPTI. In contrast, inactivation of GH action in the LID + GHa mice resulted in an increase in PPAR $\alpha$ levels similar to those in controls and a corresponding increase in ACO and CPTI mRNA levels similar to those in control mice.
In summary, we have analyzed the effects of both excess GH and GH inactivation in a mouse model of liver-specific IGF-1 deficiency. We demonstrated that chronic elevation of $\mathrm{GH}$ secretion (which results from decreased circulating IGF-1) in the LID mice antagonizes insulin action in peripheral tissues, thereby causing insulin insensitivity and hyperinsulinemia (Figure 7). Inactivation of $\mathrm{GH}$ action concomitantly with decreased levels of IGF-1 (in LID + GHa mice) lead to a state of enhanced insulin sensitivity, as reflected by decreased levels of blood glucose and insulin, decreased insulin tolerance, and increased insulin-stimulated glucose uptake in muscle and fat tissues.

In conclusion, these results suggest that chronic elevation of GH levels is a major cause of insulin resistance in the LID mouse model. The results of the present study support the studies of Rose and Clemmons (52), which applied the GHa peptide for the treatment of acromegalic patients, who have high levels of $\mathrm{GH}$ and as a result develop poor glycemic control. Treatment of such patients with a GH antagonist might improve their insulin sensitivity. The findings further imply that IGF-1 plays a lesser role in the sensitization of insulin actions, but rather acts to maintain a fine balance between circulating GH levels and insulin's action, thereby promoting normal carbohydrate and lipid metabolism.

\section{Acknowledgments}

The authors wish to thank Oksana Gavrilova (Bethesda, Maryland, USA) for helpful discussions and A.F. Parlow (National Hormone and Pituitary Program, Harbor-UCLA Medical Center, Torrance, California, USA) for help in establishing the IGF-1 and GH RIA.

1. Houssay, B.A. 1936. The hypophysis and metabolism. N. Engl. J. Med. 214:961.

2. Moller, N., et al. 1991. Effects of growth hormone on glucose metabolism. Horm. Res. 36(Suppl 1):32-35.

3. Davidson, M.B. 1987. Effect of growth hormone on carbohydrate and lipid metabolism. Endocr. Rev. 8:115-131.

4. Beauville, M., et al. 1992. Effect of long-term rhGH administration in GHdeficient adults on fat cell epinephrine response. Am. J. Physiol. 263:E467-E472

5. Kamel, A., Norgren, S., Elimam, A., Danielsson, P., and Marcus, C. 2000 Effects of growth hormone treatment in obese prepubertal boys. J. Clin. Endocrinol. Metab. 85:1412-1419.

6. Dominici, F.P., Arostegui Diaz, G., Bartke, A., Kopchick, J.J., and Turyn, D. 2000. Compensatory alterations of insulin signal transduction in liver of growth hormone receptor knockout mice. J. Endocrinol. 166:579-590.

7. Argetsinger, L.S., et al. 1995. Growth hormone, interferon-gamma, and leukemia inhibitory factor promoted tyrosyl phosphorylation of insulin receptor substrate-1. J. Biol. Chem. 270:14685-14692.

8. Argetsinger, L.S., Norstedt, G., Billestrup, N., White, M.F., and Carter-Su, C. 1996. Growth hormone, interferon-gamma, and leukemia inhibitory factor utilize insulin receptor substrate-2 in intracellular signaling. J. Biol. Chem. 271:29415-29421.

9. Thirone, A.C., Carvalho, C.R., and Saad, M.J. 1999. Growth hormone stimulates the tyrosine kinase activity of JAK2 and induces tyrosine phosphorylation of insulin receptor substrates and Shc in rat tissues. Endocrinology. 140:55-62.

10. VanderKuur, J., Allevato, G., Billestrup, N., Norstedt, G., and Carter-Su, C. 1995. Growth hormone-promoted tyrosyl phosphorylation of SHC proteins and SHC association with Grb2. J. Biol. Chem. 270:7587-7593.

11. Vanderkuur, J.A., et al. 1997. Signaling molecules involved in coupling growth hormone receptor to mitogen-activated protein kinase activation. Endocrinology. 138:4301-4307.

12. Kilgour, E., Gout, I., and Anderson, N.G. 1996. Requirement for phosphoinositide 3-OH kinase in growth hormone signalling to the mitogen-activated protein kinase and p70s6k pathways. Biochem. J. 315:517-522. 
13. Adams, T.E., et al. 1998. Growth hormone preferentially induces the rapid, transient expression of SOCS-3, a novel inhibitor of cytokine receptor signaling. J. Biol. Chem. 273:1285-1287.

14. Mooney, R.A., et al. 2001. Suppressors of cytokine signaling-1 and - 6 associate with and inhibit the insulin receptor. A potential mechanism for cytokine-mediated insulin resistance. J. Biol. Chem. 276:25889-25893.

15. Peraldi, P., Filloux, C., Emanuelli, B., Hilton, D.J., and Van Obberghen, E. 2001. Insulin induces suppressor of cytokine signaling-3 tyrosine phosphorylation through Janus-activated kinase. J. Biol. Chem. 276:24614-24620.

16. Dey, B.R., Furlanetto, R.W., and Nissley, P. 2000. Suppressor of cytokine signaling (SOCS)-3 protein interacts with the insulin-like growth factor-I receptor. Biochem. Biophys. Res. Commun. 278:38-43.

17. Emanuelli, B., et al. 2000. SOCS-3 is an insulin-induced negative regulator of insulin signaling. J. Biol. Chem. 275:15985-15991.

18. Rui, L., Yuan, M., Frantz, D., Shoelson, S., and White, M.F. 2002. SOCS-1 and SOCS-3 block insulin signaling by ubiquitin-mediated degradation of IRS1 and IRS2. J. Biol. Chem. 277:42394-42398.

19. Kawazoe, Y., et al. 2001. Signal transducer and activator of transcription (STAT)-induced STAT inhibitor 1 (SSI-1)/suppressor of cytokine signaling 1 (SOCS1) inhibits insulin signal transduction pathway through modulating insulin receptor substrate 1 (IRS-1) phosphorylation. J. Exp. Med. 193:263-269

20. Krebs, D.L., et al. 2002. SOCS-6 binds to insulin receptor substrate 4, and mice lacking the SOCS-6 gene exhibit mild growth retardation. Mol. Cell Biol. 22:4567-4578

21. Yakar, S., et al. 2001. Liver-specific igf-1 gene deletion leads to muscle insulin insensitivity. Diabetes. 50:1110-1118.

22. Chen, W.Y., White, M.E., Wagner, T.E., and Kopchick, J.J. 1991. Functional antagonism between endogenous mouse growth hormone $(\mathrm{GH})$ and a $\mathrm{GH}$ analog results in dwarf transgenic mice. Endocrinology. 129:1402-1408.

23. Yakar, S., et al. 1999. Normal growth and development in the absence of hepatic insulin-like growth factor I. Proc. Natl. Acad. Sci. U. S. A. 96:7324-7329.

24. Burant, C.F., et al. 1997. Troglitazone action is independent of adipose tissue. J. Clin. Invest. 100:2900-2908.

25. Gavrilova, O., et al. 1999. Torpor in mice is induced by both leptin-dependent and -independent mechanisms. Proc. Natl. Acad. Sci. U. S. A. 96:14623-14628

26. Kim, J.K., et al. 2000. Redistribution of substrates to adipose tissue promotes obesity in mice with selective insulin resistance in muscle. J. Clin. Invest. 105:1791-1797.

27. MacLeod, J.N., and Shapiro, B.H. 1988. Repetitive blood sampling in unrestrained and unstressed mice using a chronic indwelling right atrial catheterization apparatus. Lab. Anim. Sci. 38:603-608.

28. Colombo, C., et al. 2003. Opposite effects of background genotype on muscle and liver insulin sensitivity of lipoatrophic mice. Role of triglyceride clearance. J. Biol. Chem. 278:3992-3999.

29. Kieffer, T.J., Heller, R.S., and Habener, J.F. 1996. Leptin receptors expressed on pancreatic beta-cells. Biochem. Biophys. Res. Commun. 224:522-527.

30. Ceddia, R.B., William, W.N., Jr., Carpinelli, A.R., and Curi, R. 1999. Modulation of insulin secretion by leptin. Gen. Pharmacol. 32:233-237.

31. Tanizawa, Y., et al. 1997. Direct stimulation of basal insulin secretion by physiological concentrations of leptin in pancreatic beta cells. Endocrinology. 138:4513-4516.

32. Shimomura, I., et al. 2000. Decreased IRS-2 and increased SREBP-1c lead to mixed insulin resistance and sensitivity in livers of lipodystrophic and $o b / o b$ mice. Mol. Cell. 6:77-86.

33. Bartke, A., et al. 1999. Effects of growth hormone overexpression and growth hormone resistance on neuroendocrine and reproductive functions in transgenic and knock-out mice. Proc. Soc. Exp. Biol. Med. 222:113-123.

34. Lippe, B.M., Kaplan, S.A., Golden, M.P., Hendricks, S.A., and Scott, M.L 1981. Carbohydrate tolerance and insulin receptor binding in children with hypopituitarism: response after acute and chronic human growth hormone administration. J. Clin. Endocrinol. Metab. 53:507-513.

35. Merimee, T.J., Felig, P., Marliss, E., Fineberg, S.E., and Cahill, G.G., Jr. 1971. Glucose and lipid homeostasis in the absence of human growth hormone. J. Clin. Invest. 50:574-582.

36. Grunt, J.A., Crigler, J.F., Jr., Slone, D., and Soeldner, J.S. 1967. Changes in serum insulin, blood sugar, and free fatty acid levels four hours after administration of human growth hormone to fasting children with short stature. Yale J. Biol. Med. 40:68-74.

37. Costin, G., Kogut, M.D., and Frasier, S.D. 1972. Effect of low-dose human growth hormone on carbohydrate metabolism in children with hypopituitarism. J. Pediatr. 80:796-803.

38. Bougneres, P.F., Artavia-Loria, E., Ferre, P., Chaussain, J.L., and Job, J.C. 1985 Effects of hypopituitarism and growth hormone replacement therapy on the production and utilization of glucose in childhood. J. Clin. Endocrinol. Metab. 61:1152-1157.

39. Daugaard, J.R., Laustsen, J.L., Hansen, B.S., and Richter, E.A. 1999. Insulin action in growth hormone-deficient and age-matched control rats: effect of growth hormone treatment. J. Endocrinol. 160:127-135.

40. Altszuler, N. 1974. Actions of growth hormone and carbohydrate metabolism. American Physiological Society. Washington, DC, USA. 233-252.
41. De Bodo, R.C., and Altszuler, N. 1958. Insulin hypersensitivity and physiological insulin antagonists. Physiol. Rev. 38:389-445.

42. Sonksen, P.H., et al. 1967. Changes of carbohydrate tolerance in acromegaly with progress of the disease and in response to treatment. J. Clin. Endocrinol. Metab. 27:1418-1430.

43. Liebermeister, H., et al. 1968. Serum insulin in acromegaly. Comparative investigations by a radio-immunological method and the biological methods using adipose and muscle tissue. Diabetologia. 4:195-202.

44. Elkeles, R.S., Wright, A.D., Lowy, C., and Fraser, T.R. 1969. Serum-insulin in acromegaly. Lancet. 2:615-618.

45. Akerblom, H.K., Newman, P.R., Meakin, J.W., Martin, J.M., and Simpson, W.J. 1969. Insulin and growth hormone responses to glucose loading in treated acromegalics. Diabetologia. 5:183-187.

46. Trimble, E.R., Atkinson, A.B., Buchanan, K.D., and Hadden, D.R. 1980. Plasma glucagon and insulin concentrations in acromegaly. J. Clin. Endocrinol. Metab. 51:626-631.

47. Sato, K., Takamatsu, K., and Hashimoto, K. 1995. Short-term effects of octreotide on glucose tolerance in patients with acromegaly. Endocr. $J$. 42:739-745.

48. Hansen, I., et al. 1986. Insulin resistance in acromegaly: defects in both hepatic and extrahepatic insulin action. Am. J. Physiol. 250:E269-E273.

49. Foss, M.C., et al. 1991. Peripheral glucose metabolism in acromegaly. J. Clin Endocrinol. Metab. 72:1048-1053.

50. Ho, K.K., Jenkins, A.B., Furler, S.M., Borkman, M., and Chisholm, D.J. 1992. Impact of octreotide, a long-acting somatostatin analogue, on glucose tolerance and insulin sensitivity in acromegaly. Clin. Endocrinol. (Oxf). 36:271-279

51. van der Lely, A.J., et al. 2001. Long-term treatment of acromegaly with pegvisomant, a growth hormone receptor antagonist. Lancet. 358:1754-1759.

52. Rose, D.R., and Clemmons, D.R. 2002. Growth hormone receptor antagonist improves insulin resistance in acromegaly. Growth Horm. IGF Res. 12:418-424.

53. O'Connell, T., and Clemmons, D.R. 2002. IGF-I/IGF-binding protein-3 combination improves insulin resistance by GH-dependent and independent mechanisms. J. Clin. Endocrinol. Metab. 87:4356-4360.

54. Carrel, A.L., and Allen, D.B. 2000. Effects of growth hormone on adipose tissue. J. Pediatr. Endocrinol. Metab. 13(Suppl 2):1003-1009.

55. Nam, S.Y., and Marcus, C. 2000. Growth hormone and adipocyte function in obesity. Horm. Res. 53(Suppl 1):87-97.

56. Richelsen, B., et al. 1994. Growth hormone treatment of obese women for 5 wk: effect on body composition and adipose tissue LPL activity. Am. J. Physiol. 266:E211-E216.

57. Goodman, H.M. 1968. Growth hormone and the metabolism of carbohydrate and lipid in adipose tissue. Ann. N. Y. Acad. Sci. 148:419-440.

58. Carroll, P.V., et al. 1998. Growth hormone deficiency in adulthood and the effects of growth hormone replacement: a review. Growth Hormone Research Society Scientific Committee. J. Clin. Endocrinol. Metab. 83:382-395.

59. Salomon, F., Cuneo, R.C., Hesp, R., and Sonksen, P.H. 1989. The effects of treatment with recombinant human growth hormone on body composition and metabolism in adults with growth hormone deficiency. N. Engl.J. Med. 321:1797-1803.

60. Boni-Schnetzler, M., Gosteli-Peter, M.A., Moritz, W., Froesch, E.R., and Zapf, J. 1996. Reduced ob mRNA in hypophysectomised rats is not restored by growth hormone $(\mathrm{GH})$, but further suppressed by exogenously administered insulin-like growth factor (IGF) I. Biochem. Biophys. Res. Commun. 225:296-301.

61. Boni-Schnetzler, M., Hauri, C., and Zapf, J. 1999. Leptin is suppressed during infusion of recombinant human insulin-like growth factor I (rhIGF I) in normal rats. Diabetologia. 42:160-166.

62. Berger,J., and Moller, D.E. 2002. The mechanisms of action of PPARs. Annu Rev. Med. 53:409-435.

63. Reddy, J.K., and Hashimoto, T. 2001. Peroxisomal beta-oxidation and peroxisome proliferator-activated receptor alpha: an adaptive metabolic system. Annu. Rev. Nutr. 21:193-230.

64. Johnson, E.F., Palmer, C.N., Griffin, K.J., and Hsu, M.H. 1996. Role of the peroxisome proliferator-activated receptor in cytochrome P450 4A gene regulation. FASEB J. 10:1241-1248.

65. Aoyama, T., et al. 1998. Altered constitutive expression of fatty acid-metabolizing enzymes in mice lacking the peroxisome proliferator-activated receptor alpha (PPARalpha). J. Biol. Chem. 273:5678-5684.

66. Moody, D.E., Loury, D.N., and Hammock, B.D. 1985. Epoxide metabolism in the liver of mice treated with clofibrate (ethyl-alpha-(p-chlorophenoxyisobutyrate], a peroxisome proliferator. Toxicol. Appl. Pharmacol. 78:351-362.

67. Carlsson, L., Linden, D., Jalouli, M., and Oscarsson, J. 2001. Effects of fatty acids and growth hormone on liver fatty acid binding protein and PPARalpha in rat liver. Am. J. Physiol. Endocrinol. Metab. 281:E772-E781.

68. Chinetti, G., et al. 2001. PPAR-alpha and PPAR-gamma activators induce cholesterol removal from human macrophage foam cells through stimulation of the ABCA1 pathway. Nat. Med. 7:53-58.

69. Brady, P.S., Marine, K.A., Brady, L.J., and Ramsay, R.R. 1989. Co-ordinate induction of hepatic mitochondrial and peroxisomal carnitine acyltransferase synthesis by diet and drugs. Biochem. J. 260:93-100. 